\title{
ADVANCEMENT AND SYNCHRONISATION OF SPAWNING IN SALMO GAIRDNERI AND $S$. TRUTTA FOLLOWING ADMINISTRATION OF LRH-A COMBINED OR NOT WITH PIMOZIDE
}

\author{
R. BILLARD, P. REINAUD, M.G. HOLLEBECQ and B. BRETON \\ Laboratoire de Physiologie des Poissons et Station de Physiologie Animale, I.N.R.A., \\ Campus de Beaulieu, F-35042 Rennes and 78350 Jouy en Josas (France)
}

\section{ABSTRACT}

Billard, R., Reinaud, P., Hollebecq, M.G. and Breton, B., 1984. Advancement and synchronisation of spawning in Salmo gairdneri and $S$. trutta following administration of LRH-A combined or not with pimozide. Aquaculture, 43:57-66.

Prior to the onset of the spawning season female rainbow trout were injected intraperitoneally (IP) with LRH-A ([des Gly ${ }^{10}$ D-Ala $\left.{ }^{6}\right]$ LHRH ethylamide) alone at a dose of $1 \mu \mathrm{g} / \mathrm{kg}$ body weight or in combination with pimozide (PIM, $10 \mathrm{mg} / \mathrm{kg}$ body weight), a dopamine antagonist, given $6 \mathrm{~h}$ before the LRH-A. Pimozide + LRH-A and pimozide alone induced a significant elevation in plasma GTH but only PIM + LRH-A consistently advanced ovulation. Egg quality was altered with PIM + LRH-A and PIM + saline, resulting in lower survival at the eyed stage.

Prior to the onset of the spawning period, brown trout were injected IP with LRH-A alone at doses of 1,10 and $20 \mu \mathrm{g} / \mathrm{kg}$ body weight. A single injection slightly initiated and synchronized ovulation at doses of 10 and $20 \mu \mathrm{g}$; a second injection given 6 days later did not modify the ovulation profile. There was no effect when the same doses were given in pelleted form in silicone rubber implants. When LRH-A and PIM were injected IP $6 \mathrm{~h}$ apart at doses of 10 and $1 \mathrm{mg} / \mathrm{kg}$ body weight PIM and $10 \mu \mathrm{g} / \mathrm{kg}$ body weight LRH-A, ovulation was slightly stimulated. The effects of LRH-A given in silicone rubber implants were potentiated by simultaneous injection of PIM (10 $\mathrm{mg} / \mathrm{kg}$ body weight). No alteration of egg quality was observed after these various treatments on brown trout.

\section{INTRODUCTION}

LRH and its anlog, LRH-A ([des Gly ${ }^{10}$ D-Ala $\left.{ }^{6}\right]$ LHRH ethylamine), have been successfully used to induce oocyte maturation and ovulation in some fish species: cyprinids (Anon., 1975; Breton et al., 1983; Kouril et al., 1983; Billard et al., 1984), salmonids (Donaldson et al., 1981; Van der Kraak et al., 1982; Crim et al., 1983a,b), sea bass (Barnabé and Paris, 1984; Zohar et al., 1984) and sturgeon (Doroshov and Lutes, 1984). Normally, it has been necessary to use high doses; however, these doses could possibly be decreased by employing an antidopamine compound, such as pimozide, which removes the dopamine inhibition of GTH secretion (Crim, 1982; Chang and Peter, 1983a,b; Chang et al., 1983). This potentiation of the 
effect of LRH-A has been shown in goldfish (Chang and Peter, 1983a,b; Sokolowska et al., 1984) and in carp (Billard et al., 1983) but thus far not in salmonids.

In the present work, LRH-A was tested alone or in combination with pimozide on rainbow trout and brown trout. The pimozide was usually given before the LRH-A so that dopamine inhibition would be blocked when the LRH-A was administered. To avoid handling the fish twice, we tried in one experiment to administer LRH-A in an implant (according to Weil and Crim, 1983) at the same time as the pimozide. A high and continuous release of GTH was to be expected. GTH has been shown to be a prime factor in the induction in vitro of $17 \alpha-20 \beta$-progesterone secretion (Zohar, 1982).

\section{MATERIAL AND METHODS}

Experiment 1: effects of pimozide $+L R H-A$ administered in rainbow trout on GTH secretion and advancement of ovulation

Adult female rainbow trout (winter-spawning strain) weighing 800-2000 $\mathrm{g}$ and bred since hatching in the Gournay fish farm were brought to our laboratory in mid-October. They were kept in experimental facilities in recycled water under natural temperature $\left(7-15^{\circ} \mathrm{C}\right)$ and photoperiod. On 15 November, a few weeks before the onset of spawning, they were divided into four groups of seven to eight females each and given the following treatments: the control group (group 1) was given pimozide solvent (vehicle) and LRH-A solvent (physiological saline: PS); group 2 received pimozide (PIM) + PS; group 3 received vehicle + LRH-A; and group 4 was given PIM + LRH-A. Pimozide or vehicle was injected into the fish at $10.00 \mathrm{~h}$ and LRH-A or PS was given $6 \mathrm{~h}$ later. The pimozide (Janssen Lebrun, rue Lubeck, Paris), injected at a dose of $10 \mathrm{mg} / \mathrm{kg}$ body weight, was suspended in $1 \mathrm{ml}$ acidified saline (vehicle: $\mathrm{NaCl} 7 \mathrm{~g}$, Na metabisulfite $1 \mathrm{~g}$, acetic acid $200 \mu$ l, distilled water 1 l) and mixed with an Ultraturax grinder. The LRH-A ([des Gly ${ }^{10}$ D-Ala ${ }^{6}$ ] LHRH ethylamide; Sigma) was dissolved in a $7 \% \mathrm{NaCl}$ solution and injected at a dose of $1 \mu \mathrm{g} / \mathrm{kg}$ body weight. The fish were checked for ovulation by hand stripping. Blood was taken before the first injection and sampled $2,4,6,10,14,22,33$ and 49 days later. The plasma was frozen until radioimmunoassayed for t-GTH (S-GTH equivalent) according to Breton et al. (1983). Batches of approximately 200 eggs were taken from each female and fertilized with milt taken from several males. The eggs were incubated at $10^{\circ} \mathrm{C}$ for $20-25$ days. To determine the percentage of eyed eggs, the developing eggs were counted after clearing in Stockard solution. 
Experiment 2: effects of administering $L R H$-A alone or in combination with pimozide on the synchronization of ovulation in brown trout

This experiment was carried out in the second half of November on 4year-old brown trout (second reproductive cycle) in the Vermenoux hatchery (Nièvre, France). Each group had 20 females which had spawned the previous year between mid-November and the end of December. LRH-A $(1,10$ and $20 \mu \mathrm{g} / \mathrm{kg}$ body weight) was given alone first by intraperitoneal injection or in a silicone rubber implant ( $\mathrm{Si}$ ) (Medical elastomer 382; Dow Corning) in the morning, according to the method of Lotz and Syllwasschy (1979) in rat and Weil and Crim (1983) in Salmo salar. In a second trial using the same design as experiment 1, LRH-A was combined with pimozide, which was injected in the morning $6 \mathrm{~h}$ before the LRH-A. Pimozide was given at a dose of 1 or $10 \mathrm{mg} / \mathrm{kg}$ body weight and LRH-A at 1 or $10 \mu \mathrm{g}$. A control group received only the vehicle and PS; the other groups received PIM + PS, vehicle + LRH-A or PIM + LRH-A. Each group had 15 females. In an additional trial, pimozide $(10 \mathrm{mg} / \mathrm{kg}$ body weight $)$ or vehicle was injected at the same time as the LRH-A silicone rubber implant ( 5 and 50 $\mu \mathrm{g} / \mathrm{kg}$ body weight); each group had 10 females. The fish were checked periodically for ovulation; the eggs were counted and their number estimated (fecundity). Egg fertility was estimated by the percentage of eyed and hatched eggs. During the experiments, the water temperature varied between 4 and $7^{\circ} \mathrm{C}$.

Variance analysis (ANOVA) was used for a statistical comparison of the percentage of eyed eggs (after angular transformation of the percentage) and GTH levels.

\section{RESULTS}

Experiment 1: effects of pimozide + LRH-A administered in rainbow trout on GTH secretion and advancement of ovulation

The profile of plasma GTH and the percentage of ovulated females are given in Fig. 1. Pimozide alone (PIM + PS) or PIM + LRH-A significantly increased the level of GTH 2 days after injection, compared to the group receiving only LRH-A and the solvents. GTH remained significantly higher in the PIM + PS or PIM + LRH-A groups 6 days after the injections. Ovulation was only markedly advanced in the group injected with PIM + LRH-A (group $4)$; in the PIM + PS group ovulation was only slightly higher than in the other groups, although the level of GTH had increased. Egg fertility (Table I) was highly variable. The percentage of eyed eggs was low and variable in groups 2 and 4 which received pimozide, although the females were checked frequently for ovulation (about every 4 days). There was no correlation between fertility and sampling frequency. In the other groups (control or LRH-A alone), the percentage of eyed eggs was higher and less variable. 
Sampling was less frequent (7-10 days) and negatively correlated with fertility, suggesting that egg quality was reduced by the pimozide treatment in groups 2 and 4.

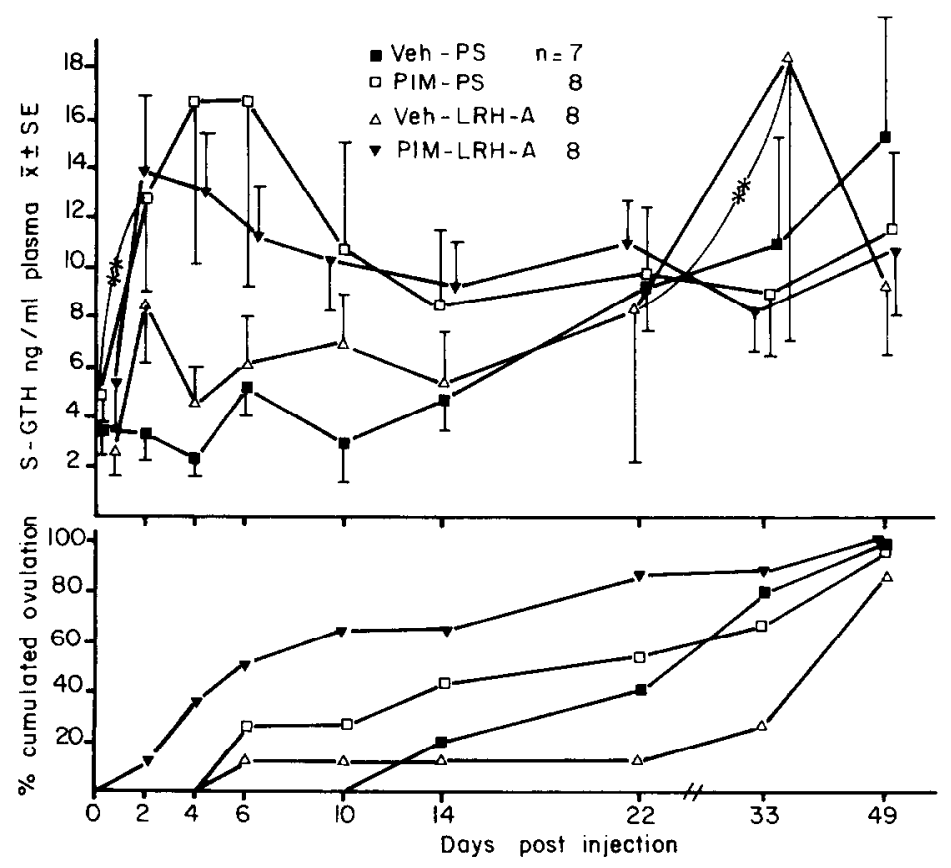

Fig. 1. Profiles of the cumulated percentage of ovulated females (bottom graph) and plasma GTH level (top graph) in rainbow trout treated with various combinations of pimozide, LRH-A and solvents.

TABLE I

Egg fertility as determined by eyed egg percentage at 250 degree-days (mean \pm SD)

\begin{tabular}{|c|c|c|c|c|c|}
\hline Group & $\begin{array}{l}\text { Treatment } \\
\text { and dose } / \mathrm{kg} \text { body wt. }\end{array}$ & $\begin{array}{l}\text { Body weight } \\
\text { (g) } \bar{X} \pm \text { SD }\end{array}$ & $\begin{array}{l}\text { Eyed-eggs } \\
\% \pm \mathrm{SD}\end{array}$ & Extreme & $\begin{array}{l}\text { Correlation } \\
\text { coefficient }^{\mathrm{a}}\end{array}$ \\
\hline $\begin{array}{l}1 \\
2 \\
3 \\
4\end{array}$ & $\begin{array}{l}\text { Vehicle + saline } \\
\text { Pimozide } 10 \mathrm{mg}+\text { saline } \\
\text { Vehicle + LRH-A } 1 \mu \mathrm{g} \\
\text { Pimozide } 10 \mathrm{mg}+\mathrm{LRH}-\mathrm{A} 1 \mu \mathrm{g}\end{array}$ & $\begin{array}{l}1465 \pm 372 \\
1436 \pm 228 \\
1548 \pm 400 \\
1362 \pm 285\end{array}$ & $\begin{array}{l}79 \pm 17 \\
54 \pm 38 \\
85 \pm 5.5 \\
54 \pm 43\end{array}$ & $\begin{array}{l}73-100 \\
9-93 * * \\
83-91 \\
0-88 * *\end{array}$ & $\begin{array}{l}0.89 \\
0.64^{*} \\
0.98 \\
0.45^{*}\end{array}$ \\
\hline
\end{tabular}

${ }^{a}$ Correlation between the percentage of eyed-eggs and the intervals between egg sampling.

Experiment 2: effects of administering LRH-A alone or in combination with pimozide on the synchronization of ovulation in brown trout

LRH-A slightly advanced ovulation in brown trout at the onset of spawning (synchronization) at doses of 10 and $20 \mu \mathrm{g} / \mathrm{kg}$ body weight; at day 9 the rate of ovulation was $20 \%$ higher than in the control or the $1 \mu \mathrm{g}$ group (Figs. 2 and 3). When a second injection of LRH-A was given on day 6, 
ovulation was not further stimulated (Fig. 3). The same doses of LRH-A (1 or $20 \mu \mathrm{g} / \mathrm{kg}$ ) administered in silicone rubber implants did not induce ovulation. Ovulation was slightly delayed in the trout at $10 \mu \mathrm{g} / \mathrm{kg}$ (Fig. 4). The number of ova stripped and the percentages of eyed and hatched eggs were similar in all groups (data not shown).

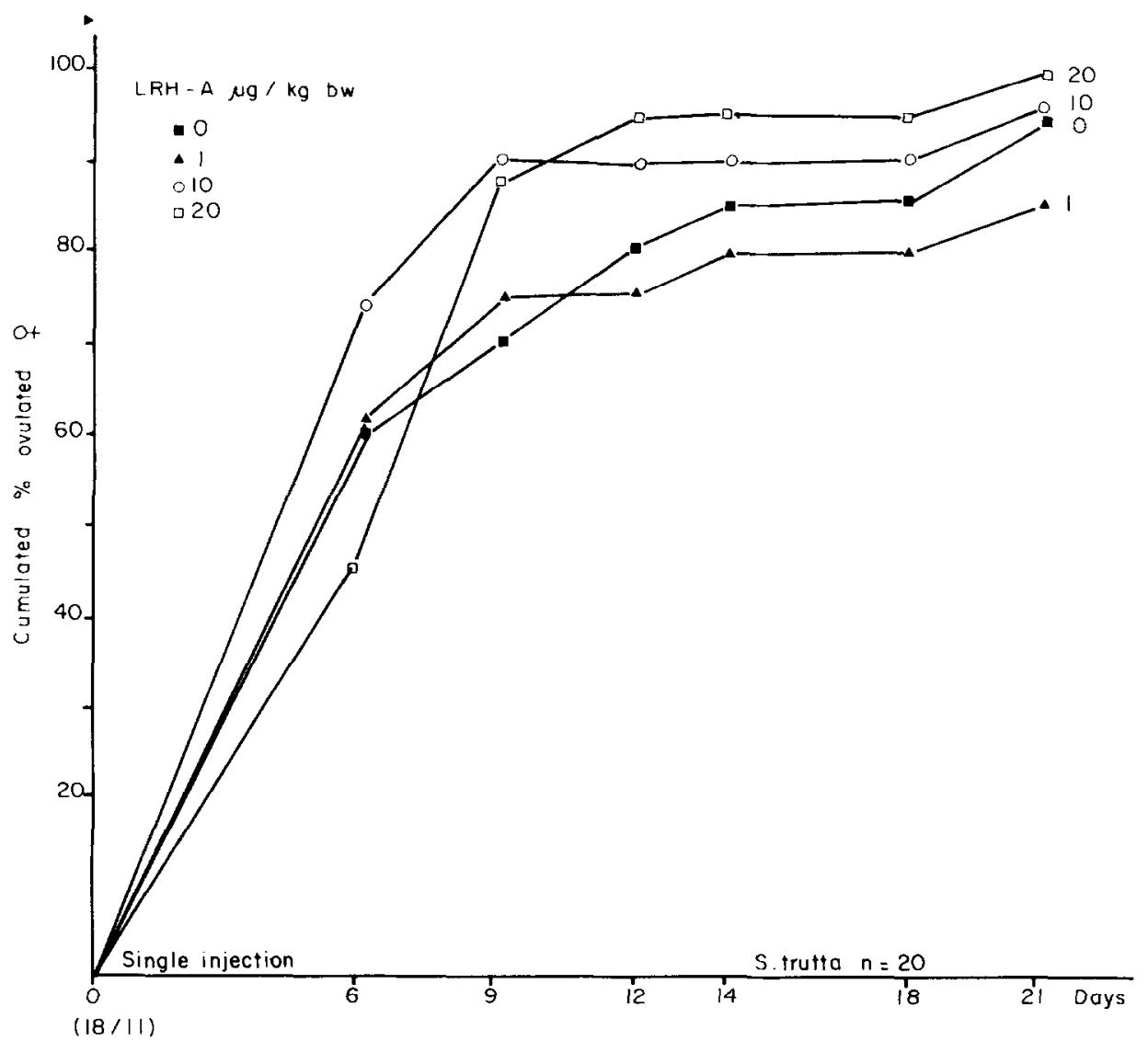

Fig. 2. Profile of the cumulated percentage of ovulated brown trout females after LRH-A treatment given in one injection.

When PIM (1-10 mg) and LRH-A $(10 \mu \mathrm{g})$ were injected $6 \mathrm{~h}$ apart, ovulation was $40-50 \%$ higher than the control at day 5 . With pimozide alone the increase was only $20 \%$. LRH-A alone $(10 \mu \mathrm{g} / \mathrm{kg})$ had a slight stimulatory effect on ovulation, $10 \%$ above the control at day 7 (Fig. 5). The LRH-A in silicone rubber implants, which had no effect on ovulation when administered alone (Fig. 4), was potentiated by simultaneous injection of pimozide $(20 \%$ more at day 4 and $50 \%$ at day $8 ; 10 \mathrm{mg} / \mathrm{kg}$ body weight; Fig. 6). There were no differences in the quantity and quality of the eggs in the various groups (data not shown). 


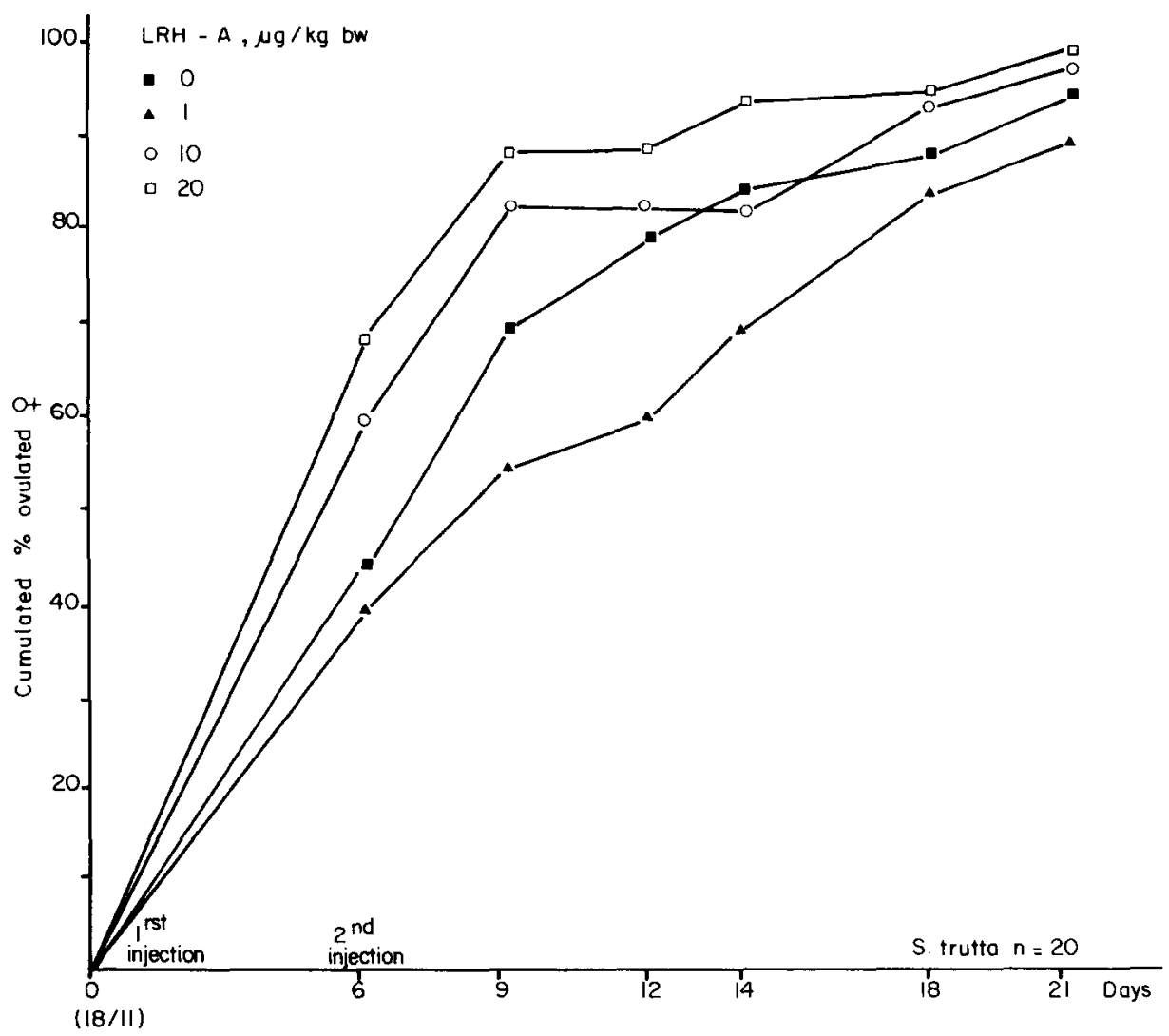

Fig. 3. Profile of the cumulated percentage of ovulated brown trout females after LRH-A treatment given in two injections 6 days apart.

\section{DISCUSSION}

In these studies, pimozide alone significantly stimulated GTH secretion but did not induce ovulation compared to controls. In the group receiving a low dose $(1 \mu \mathrm{g} / \mathrm{kg}$ body weight) of LRH-A + pimozide, there was a similar elevation in GTH with a noticeable advancement in ovulation compared with all the other groups. This indicates that a dopaminergic inhibitory system for gonadotropin secretion may exist in salmonids as has been shown in cyprinids (Chang and Peter, 1983b) and suggested by Crim (1982) in salmonids. The GTH increase in cyprinids after pimozide treatment alone is usually lower than the increase noted with pimozide treatment in combination with LRH-A (Billard et al., 1983; Sokolowska et al., 1984). In the present experiment a higher dose of LRH-A may have resulted in higher plasma GTH levels. 


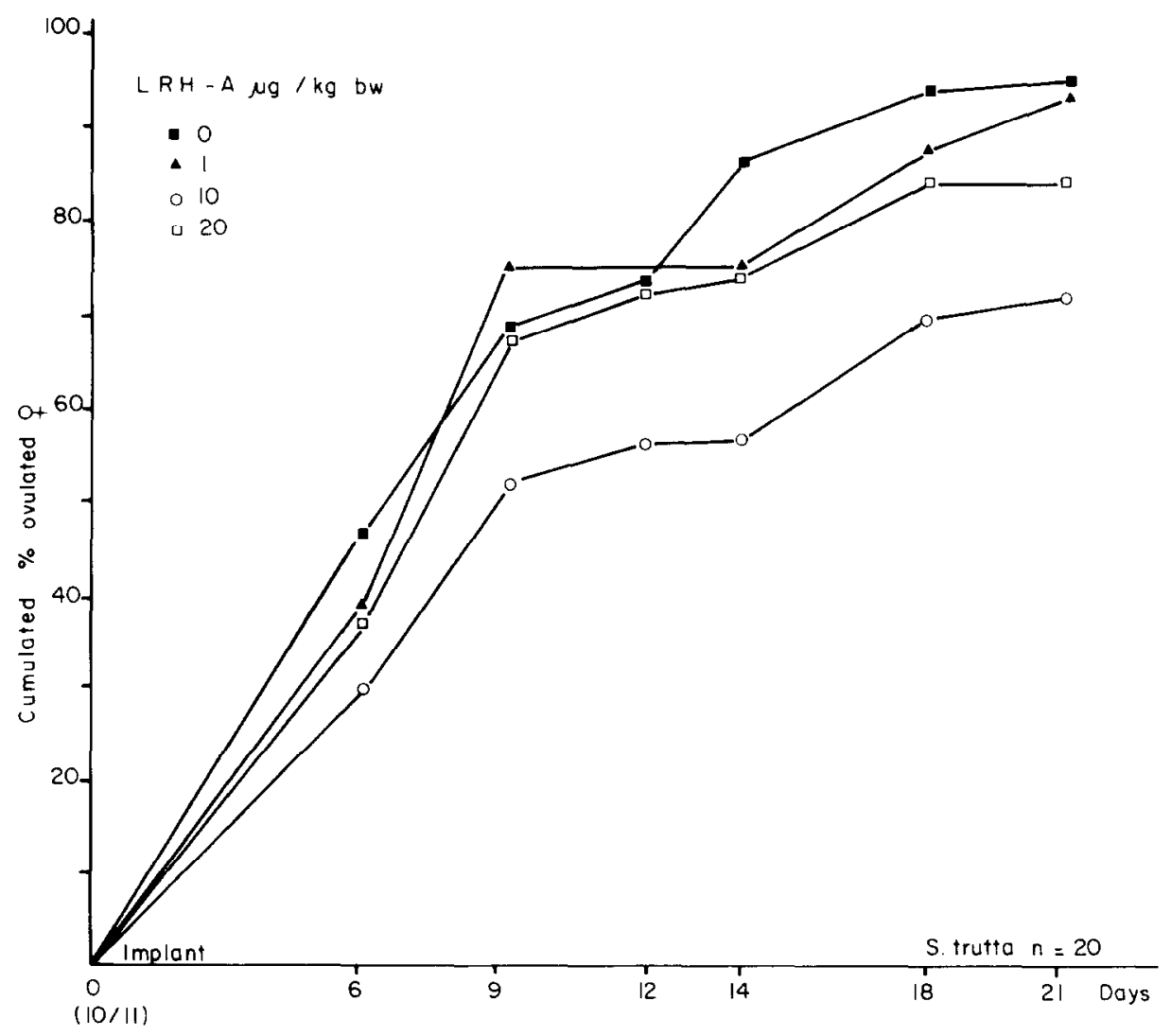

Fig. 4. Profile of the cumulated percentage of ovulated brown trout females after LRH-A treatment given in silicone rubber implant.

The poor egg quality observed in the pimozide-treated group could be due to this GTH elevation before ovulation, but poor egg quality was also noted in the pimozide + LRH-A group in which ovulation occurred at the same time as the GTH elevation, suggesting that pimozide had a direct deleterious effect on the gonads. Crim et al. (1983a) also reported poor quality and mortality in eggs taken from advanced spawners treated with pelleted LRH-A only. It may be that the poor egg quality in our experiment was due to premature application of the treatment, generating the ovulation of insufficiently mature oocytes. The absence of abnormalities in the brown trout eggs stimulated right at the onset of the spawning season, i.e., at a more advanced stage of ovarian development than that of the rainbow trout, supports that hypothesis.

It is not known why pimozide induced higher GTH levels but did not induce ovulation. It may be due to the limited number of fish in each group in which all females were late-maturing and did not respond. This is a major problem when trying to advance ovulation in salmonids. Ovulation of a 

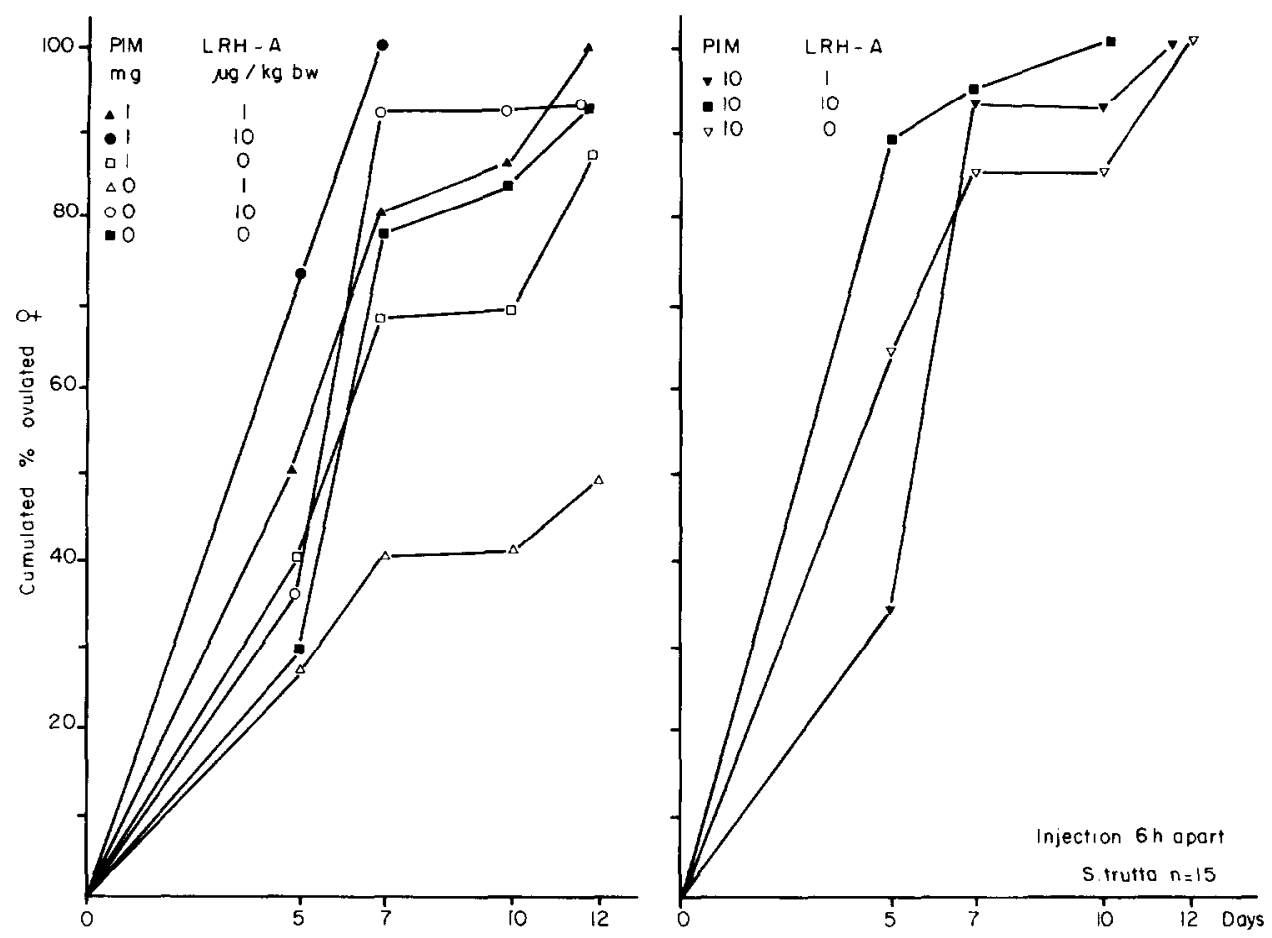

Fig. 5. Profile of the cumulated percentage of ovulated brown trout females after LRH-A treatment given in injection $6 \mathrm{~h}$ after pimozide or solvent injection.

given population occurs during a long period of time (usually several months), and only those females which are ready to ovulate in just a few weeks respond to treatment.

The state of ovarian maturity was more homogeneous in the brown trout which were grouped according to the date of ovulation the previous year. In the present study, most fish, including controls, ovulated within 1 week after the treatment. In brown trout, pimozide, even at a dose of $1 \mathrm{mg} / \mathrm{kg}$ body weight, potentiated the effect of a low dose of LRH-A on ovulation.

Pimozide alone had a more limited effect. LRH-A alone stimulated ovulation, but at higher doses (10 or $20 \mu \mathrm{g} / \mathrm{kg}$ body weight). These doses were lower than those used by Van der Kraak et al. (1982). It is interesting to note that pimozide and LRH-A can be administered at the same time; in practice, this would minimize the handling of the fish. In the present experiment, LRH-A was given via pellets but the injection route remains to be tested. Pelleted LRH-A at a dose of $20 \mu \mathrm{g} / \mathrm{kg}$ body weight did not affect ovulation in this experiment; however, it was effective in inducing ovulation at a dose of $37 \mu \mathrm{g}$ in rainbow trout (Crim et al., 1983a). 


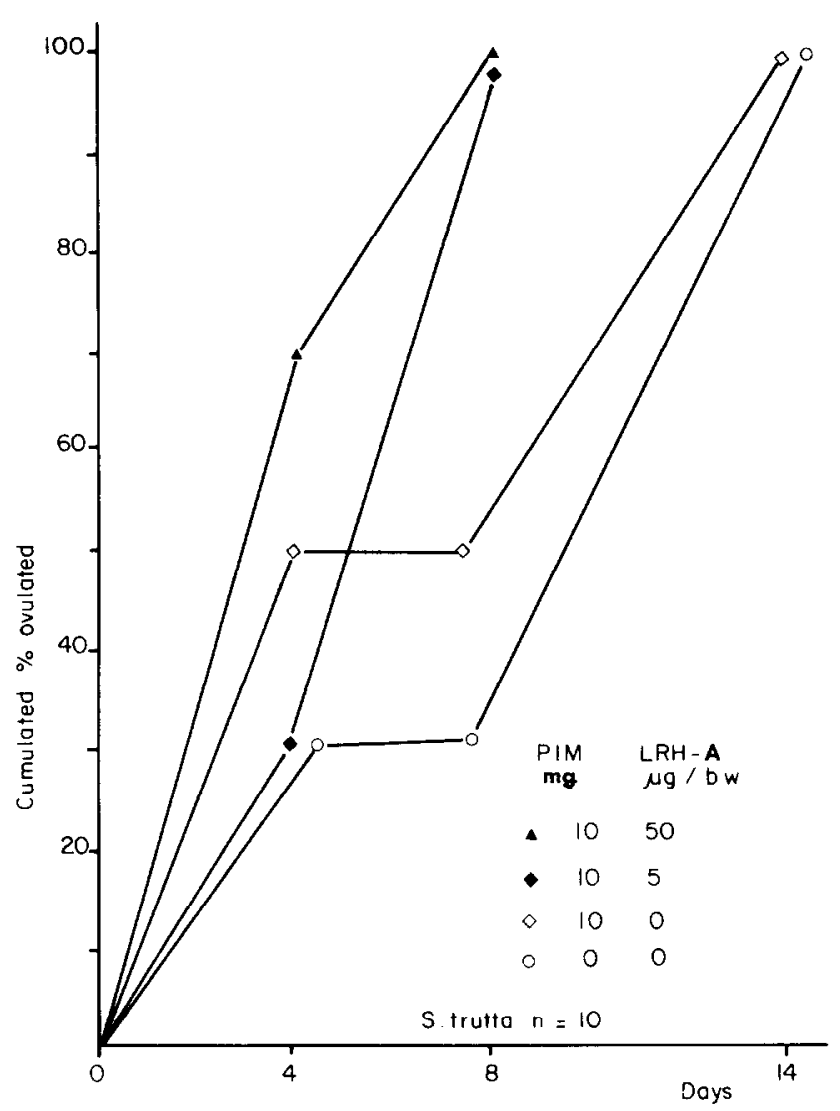

Fig. 6. Profile of the cumulated percentage of ovulated brown trout females after LRH-A treatment given in silicone rubber implant at the same time as the pimozide injection.

\section{ACKNOWLEDGEMENTS}

We wish to thank the Lebrun Laboratories for supplying the pimozide, and Alice Daifuku for the English translation of the paper. This work was supported by a CNRS-CNEXO grant "Les bases biologiques de l'Aquaculture".

\section{REFERENCES}

Anon., 1975. In: Conference on Application of Hormones to Economic Fish. Kexue Tongbao, 20: 43-48 (FMS Translation series No. 4186).

Barnabe, G. and Paris, J., 1984. Ponte avancée et ponte normale du loup Dicentrarchus labrax. In: G. Barnabé and R. Billard (Editors), L'Aquaculture du Bar et des Sparidés. INR A, Paris, pp. 6372.

Billard, R., Alagarswami, K., Peter, R.E. and Breton, B., 1983. Potentialisation par le pimozide des effets du LHRH·A sur la sécrétion gonadotrope hypophysaire, l'ovulation et la spermiation chez la carpe commune (Cyprinus carpio). C.R. Acad. Sci. Paris, Sér. t, 296: 181-184. 
Billard, R., Bieniarz, K., Peter, R.E., Sokolowka, M., Weil, C. and Crim, L.W., 1984. Effects of LHRH and LHRH-A on plasma GtH levels and maturation/ovulation in the common carp, Cyprinus carpio, kept under various environmental conditions. Aquaculture, $41: 245^{-254}$.

Breton, B., Jalabert, J., Bieniarz, K., Sokolowka, M. and Epler, P., 1983. Effects of synthetic LH-RH and analog on plasma gonadotropin levels and maturational response to $17 \alpha$-hydroxy-20 $\beta$-dihydroprogesterone. Aquaculture, 32:105-114.

Chang, J.P. and Peter, R.E., 1983a. Effects of pimozide and des-Gly ${ }^{10},\left\{\right.$ D-Ala $\left.{ }^{6}\right\}$ luteinizing hormone-releasing hormone ethylamide on serum gonadotropin concentrations, germinal vesicle migration and ovulation in female goldfish, Carassius auratus. Gen. Comp. Endocrinol., 52: 30-37.

Chang, J.P. and Peter, R.E., 1983b. Effects of dopamine on gonadotropin release in female goldfish Carassius auratus. Neuroendocrinology, $36: 351-357$.

Chang, J.P., Cook, A.F. and Peter, R.E., 1983. Influence of catecholamines on gonadotropin secretion in goldfish, Carassius auratus. Gen. Comp. Endocrinol., 49: 22-31.

Crim, L.W., 1982. Control of gonadotropic hormone secretion (GTH) by the rainbow trout pituitary gland. Evidence of GTH inhibition by catecholamine and stimulation of GTH release by some other neuroregulatory factors. In: K. Lederis and D.S. Farner (Editors), Neurosecretion. Plenum, New York, NY, p. 446.

Crim, L.W., Sutterlin, A.M., Evans, D.M. and Weil, C., 1983a. Accelerated ovulation by pelleted LHRH analogue treatment of spring-spawning rainbow trout (Salmo gairdneri) held at low temperature. Aquaculture, 35: 299-307.

Crim, L.W., Evans, D.M. and Vickery, B.H., 1983b. Manipulation of the seasonal reproductive cycle of the landlocked Atlantic salmon (Salmo salar) by LHRH analogues administered at various stages of gonadal development. Can. J. Fish. Aquat. Sci., 40: $61-67$.

Donaldson, E.M., Hunter, G.A. and Dye, H.M., 1981. Induced ovulation in coho salmon (Oncorhynchus kisutch). II. Preliminary study of the use of LH-RH and two high potency I.H-RH analogues. Aquaculture, 26: 129-141.

Doroshov, S.I. and Lutes, P.B., 1984. Preliminary data on the induction of ovulation in white sturgeon (Acipenser transmontanus Richardson). Aquaculture, 38: 221-227.

Kouril, J., Barth, T., Hamackova, J., Slaninova, J., Servitova, L., Machacek, J. and Flegel, M., 1983. Application of LH-RH and its analog for reaching ovulation in female tench, grass carp, carp and sheatfish. Bul. VÜRH Vodnany, 2: 3-16.

Lotz, W. and Syllwasschy, B., 1979. Release of oligopeptides from silicone rubber implants in rats over periods exceeding 10 days. J. Pharm. Pharmacol., 31:649-650.

Sokolowska, M., Peter, R.E., Nahorniak, C.S., Pan, C.H., Chang, J.P., Crim, L.W. and Weil, C., 1984. Induction of ovulation in goldfish, Carassius auratus, by pimozide and analogues of LH-RH. Aquaculture, 36: 71-83.

Van der Kraak, G., Lin, H.R., Donaldson, E.M., Dye, H.M. and Hunter, G.A., 1982. Effects of LH-RH and des-Gly ${ }^{10}$ \{D-Ala $\}$ LH-RH ethylamide on plasma gonadotropin levels and oocyte maturation in adult female coho salmon (Oncorhynchus kisutch). Gen. Comp. Endocrinol., 49: 470-476.

Weil, C. and Crim, L.W., 1983. Administration of LHRH analogues in various ways: effect on the advancement of spermiation in prespawning landlocked salmon, Salmo salar. Aquaculture, 35: 103-115.

Zohar, Y., 1982. L'évolution de la pulsatilité et des cycles nycthémèraux de la sécrétion gonadotrope chez la truite arc-en-ciel femelle, en relation avec le cycle sexuel annuel et par rapport â l'activité stéroīdogène de l'ovaire. Thèse Doctorat Etat, Univ, Paris VI, 273 pp.

Zohar, Y., Billard, R. and Weil, C., 1984. La reproduction de la daurade (Sparus auratus) et du bar (Dicentrarchus labrax): connaissance du cycle sexuel et contrôle de la gamétogénèse et de la ponte. In: G. Barnabé and R. Billard (Editors), L'Aquaculture du Bar et des Sparidés. INRA, Paris, pp. 3-24. 